Case Report

\title{
Acute Pancreatitis and Diabetic Ketoacidosis following L-Asparaginase/Prednisone Therapy in Acute Lymphoblastic Leukemia
}

\author{
Dania Lizet Quintanilla-Flores, ${ }^{1}$ Miguel Ángel Flores-Caballero, ${ }^{1}$ \\ René Rodríguez-Gutiérrez, ${ }^{1}$ Héctor Eloy Tamez-Pérez, ${ }^{2}$ \\ and José Gerardo González-González ${ }^{2}$ \\ ${ }^{1}$ Internal Medicine Department, "Dr. José Eleuterio González" University Hospital and School of Medicine, Universidad Autónoma de \\ Nuevo León, Avenida Francisco I. Madero pte. y Avenida Gonzalitos s/n, Colonia Mitras Centro, 64460 Monterrey, NL, Mexico \\ ${ }^{2}$ Research Division, School of Medicine, Universidad Autónoma de Nuevo León, \\ Avenida Francisco I. Madero pte. y Avenida Gonzalitos s/n, Colonia Mitras Centro, 64460 Monterrey, NL, Mexico
}

Correspondence should be addressed to Miguel Ángel Flores-Caballero; drflorescaballero@hotmail.com

Received 24 November 2013; Accepted 29 December 2013; Published 10 February 2014

Academic Editors: L. Beex, C. Gennatas, and J. I. Mayordomo

Copyright (C) 2014 Dania Lizet Quintanilla-Flores et al. This is an open access article distributed under the Creative Commons Attribution License, which permits unrestricted use, distribution, and reproduction in any medium, provided the original work is properly cited.

\begin{abstract}
Acute pancreatitis and diabetic ketoacidosis are unusual adverse events following chemotherapy based on L-asparaginase and prednisone as support treatment for acute lymphoblastic leukemia. We present the case of a 16-year-old Hispanic male patient, in remission induction therapy for acute lymphoblastic leukemia on treatment with mitoxantrone, vincristine, prednisone, and $\mathrm{L}$-asparaginase. He was hospitalized complaining of abdominal pain, nausea, and vomiting. Hyperglycemia, acidosis, ketonuria, low bicarbonate levels, hyperamylasemia, and hyperlipasemia were documented, and the diagnosis of diabetic ketoacidosis was made. Because of uncertainty of the additional diagnosis of acute pancreatitis as the cause of abdominal pain, a contrast-enhanced computed tomography was performed resulting in a Balthazar $\mathrm{C}$ pancreatitis classification.
\end{abstract}

\section{Introduction}

The long-term outcome of acute lymphoblastic leukemia (ALL) has improved dramatically during the last few decades because of the development of well-designed and effective treatment protocols. Since 1961, L-asparaginase, combined with danorubicin, vincristine, and prednisone, the cornerstone treatment for ALL. They are used in remission, induction, and intensification phases in all pediatric regimens and in the majority of adult treatment protocols $[1,2]$. Long-term, event-free, survival rates in children are currently around $80 \%$ and overall survival rates are close to or exceeding $90 \%$ of pediatric patients. Although overall survival rates in adults have improved in recent years, only $38 \%$ to $50 \%$ achieve longterm survival [3].

The most common complications associated with Lasparaginase are abdominal pain and allergic reactions. Other side effects include liver dysfunction, coagulation defects and central nervous system depression. Moreover, acute pancreatitis (AP), hyperglycemia, and diabetic ketoacidosis (DKA) can also be present [4]. Even though these side effects are well known, the combination of both DKA and AP represents unusual conditions generally reported as benign and self-limited [5].

We report a case of a 16-year-old male patient who developed transient diabetes mellitus following L-asparaginase therapy with ketoacidosis and acute pancreatitis as the mode of presentation.

\section{Case Presentation}

A 16-year-old Hispanic male patient was admitted to our hospital. He was diagnosed as having acute lymphoblastic leukemia 5 months earlier. He was during the remission 
induction phase of therapy with mitoxantrone, vincristine, prednisone, and L-asparaginase, receiving last dose one week prior to his admission. He presented to the emergency department with a history of 3 days of abdominal pain, nausea, vomiting, and anorexia, referring to his last vomiting episode as hematemesis. His blood tests reported venous gasometry resulting with a $\mathrm{pH}$ 7.27, sodium bicarbonate $15.7 \mathrm{mmol} / \mathrm{L}$, pCO2 $24 \mathrm{mmHg}$; hemoglobin $12.6 \mathrm{~g} / \mathrm{dL}(12.2-18.1 \mathrm{~g} / \mathrm{dL})$, neutrophylia of $9.58 \mathrm{cells} / \mathrm{mm}^{3}$ $\left(4.0-11.0\right.$ cells $\left./ \mathrm{mm}^{3}\right)$; hyperglycemia of $594 \mathrm{meq} / \mathrm{L} \quad(60-$ $100 \mathrm{meq} / \mathrm{L})$, blood urea nitrogen $25 \mathrm{mg} / \mathrm{dL}(7-20 \mathrm{mg} / \mathrm{dL})$, creatinine $1.17 \mathrm{mg} / \mathrm{dL}(0.6-1.4 \mathrm{mg} / \mathrm{dL})$, sodium $122 \mathrm{mmol} / \mathrm{L}$ (135-145 mmol/L); urine test with ketones; hyperamylasemia of $476 \mathrm{U} / \mathrm{L}$ (30-110 U/L), and a serum osmolarity of $282 \mathrm{mosm} / \mathrm{kg}$. The diagnosis of diabetic ketoacidosis was made.

Despite medical treatment, the patient persisted with abdominal pain and refractory hyperglycemia associated with hyperamylasemia. Because of diagnostic uncertainty a contrast-enhanced computed tomography was performed, resulting in a Balthazar $C$ pancreatitis classification. Furthermore he had a serum lipase test in 825 Units/L, confirming diagnosis of acute pancreatitis additional to the previous diagnosis of diabetic ketoacidosis.

The day after the patient was admitted, he underwent upper endoscopy, resulting in Mallory-Weiss syndrome, explaining his episode of hematemesis. After three days of fluid correction, insulin infusion, fasting, and analgesic therapy, the patient was discharged presenting no further complications.

\section{Discussion}

This case represents a combination of two rare complications related to L-asparaginase treatment during the remission induction phase of treatment in a patient with ALL. Pancreatic toxicity during L-asparaginase treatment has been reported with a prevalence of $16.2 \%$, with an incidence of AP ranging from 2 to $18 \%[3,6]$. AP results from direct deprivation on the protein metabolism leading to a disturbed synthesis of albumin, fibrinogen, plasma clotting factors IX and $\mathrm{X}$, plasminogen, and antithrombin III, which leads to considerable toxicity particularly to organs associated with high protein production such as liver and pancreas [7]. It can be observed in all phases of ALL, after a median of 5.5 doses of therapy and a median interval from the last dose of Lasparaginase administration of 4-9 days [8]. L-asparaginase AP is generally developed in patients below 10 years of age, and it has been associated with higher doses of L-asparaginase in the chemotherapy regimen $[3,8]$.

Hyperglycemia occurs in about $10-15 \%$ pediatric patients with ALL, associated with the use of L-asparaginase, glucocorticoids, AP, infection, and the leukemic process itself [9]. L-asparaginase induces hyperglycemia via depletion of L-asparagine and as a consequence decrement of insulin synthesis; additionally it decreases insulin secretion from pancreatic $\beta$-cells, impairs insulin receptor function, and causes hyperglucagonemia $[4,9]$. The risk and severity of hyperglycemia increases when L-asparaginase and glucocorticoids are used concomitantly; however it is generally self-limiting resulting in no complications [10]. Additionally, pancreatic toxicity can lead to metabolic alterations such as hyperglycemia and diabetes mellitus in $2.5-23 \%$ of patients [11].

Despite the fact that hyperglycemia is commonly associated with L-asparaginase, DKA represents a rare condition with a reported prevalence of $0.8 \%$ [9]. Older age, obesity, and Down's syndrome represent the main known risk factors for the development of DKA, with age being the only factor detected in our patient. This increased risk may be due to the association between insulin resistance and increased growth hormone secretion observed during late childhood and adolescence $[9,12]$. It is possible that the combination of Lasparaginase, glucocorticoids and AP represented synergistic factors for the development of DKA in our patient.

The clinical course of both conditions can vary from mild to severe disease. A higher mortality rate and a lower median 2-year survival associated with AP during L-asparaginase treatment have been reported [8]. On the other hand, even though overt hyperglycemia can be an independent predictor factor for survival in children with ALL during induction therapy, DKA generally results in short-term morbidity and hospital admission, without the alteration of ALL outcome and modification in the chemotherapeutic regimens $[9,13]$. Fortunately, our patient achieved complete resolution of symptoms, normalization of laboratory results, and imaging studies without major adverse events regarding both diseases.

We conclude that the combination of AP and DKA associated with L-asparaginase use are rare complications with significant morbidity and mortality. During therapy with L-asparaginase, we recommend a close monitoring for hyperglycemia as well as acute pancreatitis in order to reduce the adverse events related to both conditions.

\section{Abbreviations}

ALL: Acute lymphoblastic leukemia

AP: Acute pancreatitis

DKA: Diabetic ketoacidosis.

\section{Conflict of Interests}

The authors declare that they have no conflicts of interests regarding the publication of this paper.

\section{References}

[1] J. D. Broome, "Evidence that the L-asparaginase activity of guinea pig serum is responsible for its antilymphoma effects," Nature, vol. 191, no. 4793, pp. 1114-1115, 1961.

[2] C.-H. Pui and W. E. Evans, "Treatment of acute lymphoblastic leukemia," The New England Journal of Medicine, vol. 354, no. 2, pp. 166-178, 2006.

[3] J. Flores-Calderón, E. Exiga-Gonzaléz, S. Morán-Villota, J. Martín-Trejo, and A. Yamamoto-Nagano, "Acute pancreatitis in children with acute lymphoblastic leukemia treated with Lasparaginase," Journal of Pediatric Hematology/Oncology, vol. 31, no. 10, pp. 790-793, 2009. 
[4] S. Sahu, S. Saika, S. K. Pai, and S. H. Advani, "L-asparaginase (Leunase) induced pancreatitis in childhood acute lymphoblastic leukemia," Pediatric Hematology and Oncology, vol. 15, no. 6, pp. 533-538, 1998.

[5] M. T. Shaw, C. C. Barnes, F. J. Madden, and K. D. Bagshawe, "Lasparaginase and pancreatitis," The Lancet, vol. 2, no. 7675, p. $721,1970$.

[6] A. Morimoto, T. Imamura, R. Ishii et al., "Successful management of severe L-asparaginase-associated pancreatitis by continuous regional arterial infusion of protease inhibitor and antibiotic," Cancer, vol. 113, no. 6, pp. 1362-1369, 2008.

[7] K. Derwich, D. Stencel, M. Warzywoda, and M. Leda, "Acute pancreatitis during L-asparaginase treatment in children with acute lymphoblastic leukemia," Reports of Practical Oncology and Radiotherapy, vol. 4, no. 1, pp. 15-22, 1999.

[8] S. Treepongkaruna, N. Thongpak, S. Pakakasama, P. Pienvichit, N. Sirachainan, and S. Hongeng, "Acute pancreatitis in children with acute lymphoblastic leukemia after chemotherapy," Journal of Pediatric Hematology/Oncology, vol. 31, no. 11, pp. 812-815, 2009.

[9] J. R. Roberson, S. Raju, J. Shelso, C.-H. Pui, and S. C. Howard, "Diabetic ketoacidosis during therapy for pediatric acute lymphoblastic leukemia," Pediatric Blood \& Cancer, vol. 50, no. 6, pp. 1207-1212, 2008.

[10] A. Khan, M. Adachi, and J. M. Hill, "Potentiation of diabetogenic effect of L-asparaginase by prednisolone," Hormone and Metabolic Research, vol. 2, no. 5, pp. 275-276, 1970.

[11] R. Mondal, M. Nandi, A. Tiwari, and S. Chakravorti, "Diabetic ketoacidosis with l-asparaginase therapy," Indian Pediatrics, vol. 48, no. 9, pp. 735-736, 2011.

[12] C. H. Pui, G. A. Burghen, W. P. Bowman, and R. J. A. Aur, "Risk factors for hyperglycemia in children with leukemia receiving L-asparaginase and prednisone," The Journal of Pediatrics, vol. 99, no. 1, pp. 46-50, 1981.

[13] R. Y. Sonabend, S. V. McKay, M. F. Okcu, J. Yan, M. W. Haymond, and J. F. Margolin, "Hyperglycemia during induction therapy is associated with poorer survival in children with acute lymphocytic leukemia," The Journal of Pediatrics, vol. 155, no. 1 , pp. 73-78, 2009. 


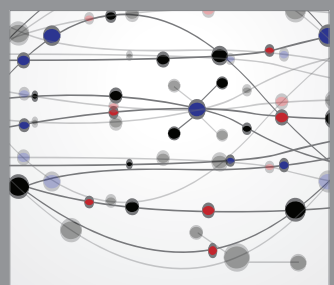

The Scientific World Journal
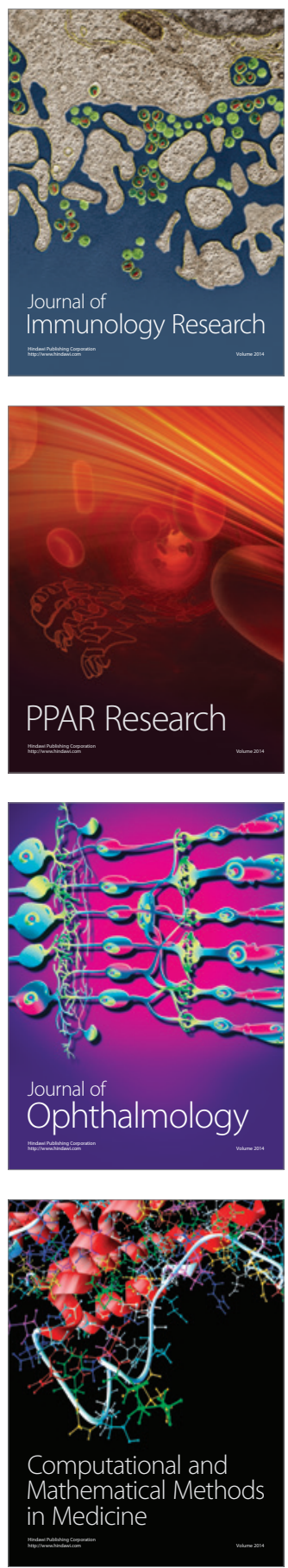

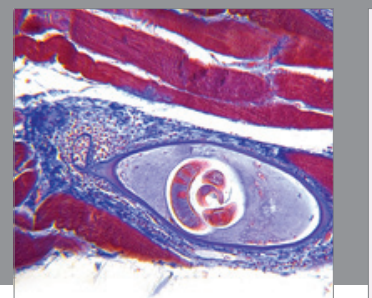

Gastroenterology

Research and Practice
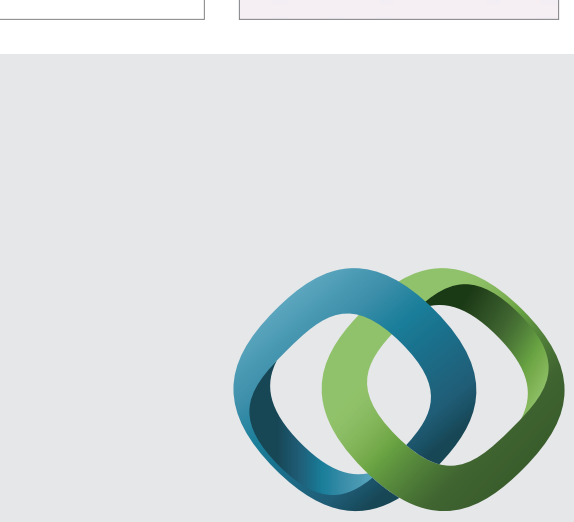

\section{Hindawi}

Submit your manuscripts at

http://www.hindawi.com
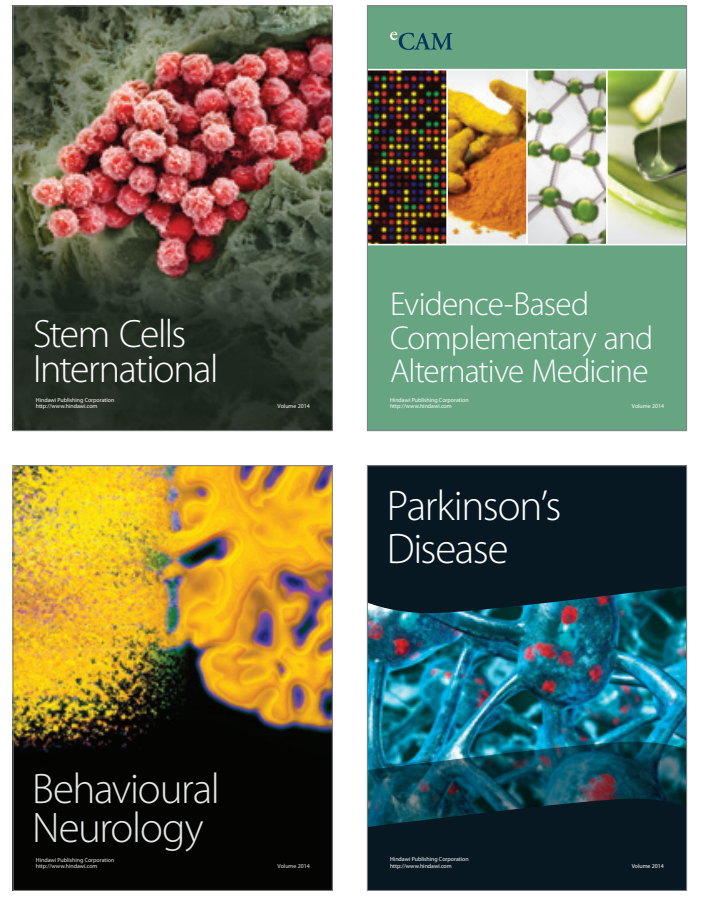
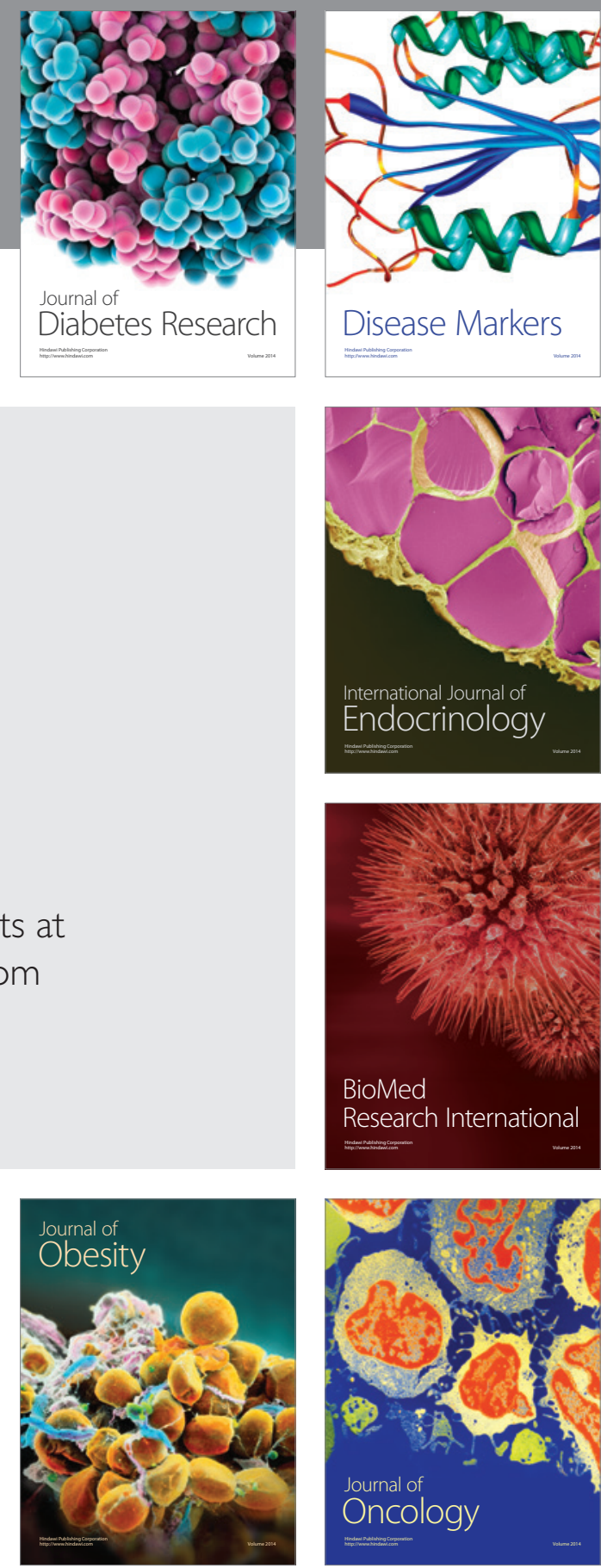

Disease Markers
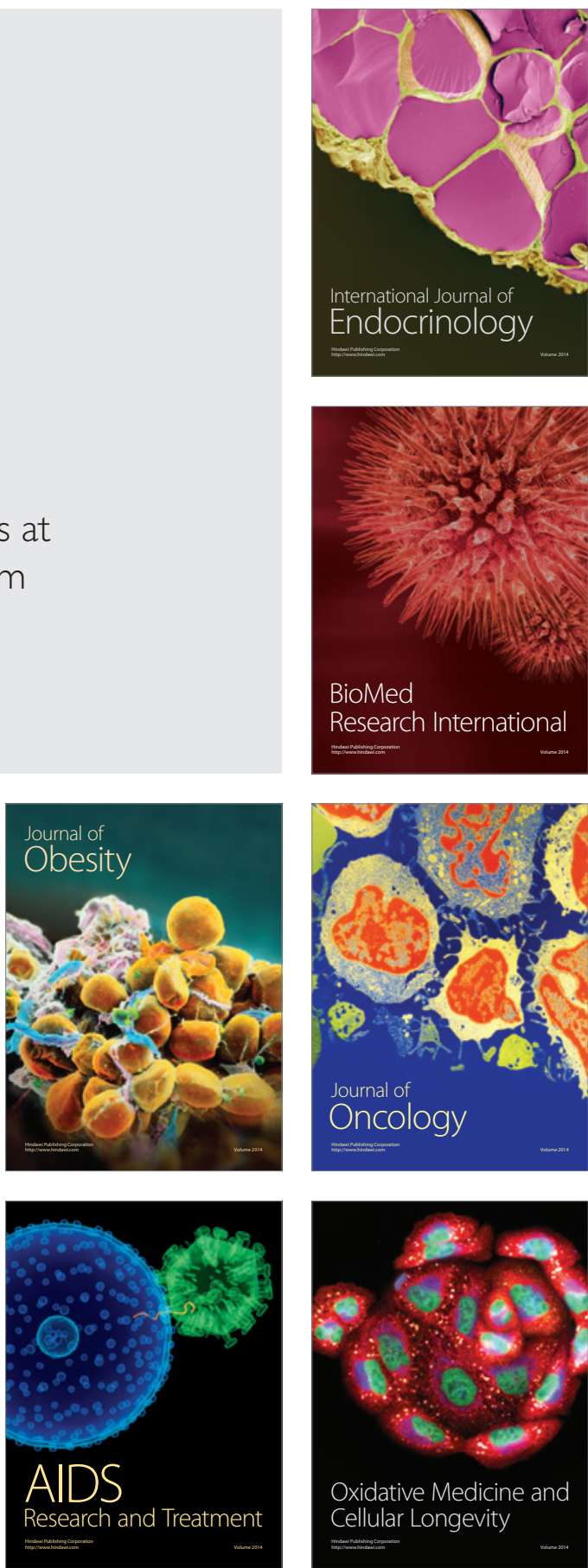